\title{
ERRATUM
}

\section{Erratum to: OnabotulinumtoxinA is Effective in Patients with Urinary Incontinence due to Neurogenic Detrusor Overactivity Regardless of Concomitant Anticholinergic Use or Neurologic Etiology}

David Ginsberg • Francisco Cruz • Sender Herschorn • Angelo Gousse • Véronique Keppenne • Philip Aliotta $\cdot$ Karl-Dietrich Sievert $\cdot$ Mitchell F. Brin • Brenda Jenkins $\cdot$ Catherine Thompson •

Wayne Lam · John Heesakkers • Cornelia Haag-Molkenteller

To view enhanced content go to www.advancesintherapy.com

Published online: February 13, 2014

(C) Springer Healthcare 2014

Erratum to: Adv Ther (2013) 30:819-833

DOI 10.1007/s12325-013-0054-z

The authors would like to make the following correction to the above mentioned article. The title should be changed from "OnabotulinumtoxinA is Effective in Patients with Urinary Incontinence due to Neurogenic

The online version of the original article can be found under doi:10.1007/s12325-013-0054-z.

\footnotetext{
D. Ginsberg $(\square)$

Department of Urology, University of Southern

California Institute of Urology, 1441 Eastlake

Avenue, NOR 7416, Los Angeles,

CA 90033-9178, USA

e-mail: ginsberg@ccnt.usc.edu

F. Cruz

Faculty of Medicine do Porto, Hospital São João,

IBMC, Porto, Portugal

S. Herschorn

University of Toronto, Toronto, Canada

\author{
A. Gousse \\ Memorial Hospital Miramar, Miramar, FL, USA \\ V. Keppenne \\ Université de Liège, Liège, Belgium \\ P. Aliotta \\ Western New York Urology Associates, \\ Cheektowaga, NY, USA
}

Detrusor Activity Regardless of Concomitant Anticholinergic Use or Neurologic Etiology" to "OnabotulinumtoxinA is Effective in Patients with Urinary Incontinence due to Neurogenic Detrusor Overactivity Regardless of Concomitant Anticholinergic Use or Neurologic Etiology".

\author{
K.-D. Sievert \\ University of Tübingen, Tübingen, Germany \\ M. F. Brin - B. Jenkins · W. Lam . \\ C. Haag-Molkenteller \\ Allergan, Inc., Irvine, CA, USA \\ M. F. Brin \\ Department of Neurology, University of California, \\ Irvine, CA, USA \\ C. Thompson \\ Allergan Ltd, Marlow, Buckinghamshire, UK \\ J. Heesakkers \\ Radboud Universiteit, Nijmegen, The Netherlands
}

